\title{
Projection View
}

National Cancer Institute

\section{Source}

National Cancer Institute. Projection View. NCI Thesaurus. Code C94959.

Detector data acquired in a specified direction from the subject. It represents a view from a certain direction. 